\title{
Report on the College's Preliminary Visit to South Africa
}

\section{February-4 March 1990}

At its meeting on 18 October 1990 Council approved the Report on the Preliminary Visit to South Africa and agreed that a summary be published in the Psychiatric Bulletin. The full report is available from the Publications Department at the College, price $£ 2.50$.

\section{Summary}

\section{Background to visit}

The College's Annual General Meeting in July 1989 passed an amended Resolution urging the Society of Psychiatrists of South Africa "to take a more active role in opposing and challenging the unethical and politically-motivated policies and practices in the field of mental health care [of the apartheid regime] and to show evidence within two years of the effect of their having done so."

Later in the same year, Council agreed that, in pursuance of this policy, there should be a preliminary visit to South Africa.

\section{The visiting team}

The visit was conducted by a team consisting of Dr Fiona Caldicott (leader of the delegation), Dr Richard Williams and Dr Peter Rice.

\section{Aims of visit}

The team's remit was:

(1) to establish an understanding of the present position of psychiatry in South Africa and to gain first-hand knowledge of the restrictions imposed upon psychiatric practice by the apartheid system

(2) To assess the current policies of the Society of Psychiatrists of South Africa (SPSA) and determine what it would be reasonable to expect the Society to achieve in the future.

The aim of the visit was not to inspect psychiatric facilities: this exercise was comprehensively carried out in 1989 by the American Association for the Advancement of Science (AAAS), whose Report accurately describes services in South Africa.

\section{Structure of health and psychiatric services in South Africa}

The organisation of all health services in South Africa is complex, with 14 separate health ministries divided according to race (the "tricameral system"), geographical area and between the public and private sectors.

The organisation of psychiatric care has been further complicated by a history of separate development and administration. From the 1940s until very recently, psychiatrists and psychologists were state employees: with the introduction of the tricameral system in 1983, responsibility for these staff and services was devolved to the health ministries. The team understands that this system has now been changed, so that psychiatrists and psychologists are employed on the staff of hospitals in the same way as other specialists.

In a country with a population of the order of 35 million, there are only about 200 trained psychiatrists: approximately half of these are in private practice. The psychiatric specialties are relatively poorly developed: for example, the number of practising child and adolescent psychiatrists is in the region of ten. Paucity of services means that each academic department of psychiatry has become responsible for provision in several widely dispersed hospitals and for community services covering large areas, with the result that academic staff have taken on major service responsibilities.

\section{Psychiatric training}

Typically, postgraduate training in psychiatry lasts for four years, with graduates entering the system at registrar level, completion is marked by obtaining the MMed, either from the College of Medicine of South Africa or from one of the university departments. At this point, trainees are eligible to apply for the equivalent of UK consultant grade posts. There is no central or co-ordinated monitoring of clinical placements and no equivalent of the senior registrar grade.

It is thought that there are only four trained black psychiatrists in the country and few in training.

Perhaps up to $50 \%$ of graduates entering specialist training are lost either to the private sector, or work abroad. 


\section{Society of Psychiatrists of South Àfrica} Function and constitution

Although the SPSA is constituted as a specialist group of the Medical Association of South Africa (MASA), it has tended to function autonomously. It has a membership of approximately 100 (half of the qualified psychiatrists in South Africa).

A great deal of the work of the Society at national level is undertaken by its Chairman and Secretary. The Society requires that the Chairman is one of the academic heads of department and that the Secretary comes from the same city. The Presidential office is filled by the outgoing Chairman. There is thus a heavy reliance on individuals who already have many teaching, administrative and service commitments in addition to their roles in the Society.

The Society has a provincial structure, with local groups arranging their own educational and representative meetings.

\section{Position of the Society with respect to apartheid in health care}

As measured by its statements over the past five years, the attitude of the SPSA has changed since 1977. In that year, the Society strongly criticised the WHO report on apartheid and mental health care, drawing a distinction between "political" issues and the function of a "non-political professional organisation". In contrast, a later statement (September 1989) addressed the need for a single national health service, providing integrated services; psychiatry and human rights; and the effect of political policies on health care. The majority of SPSA members whom the team met clearly shared these views.

However, it is apparent that the Society's current policies are not widely known to other bodies with an interest in mental health services and with whom the Society has little formal contact. This lack of effective communication and the fact that the SPSA is not regarded as a source either of support for psychiatrists in disputes with health authorities or government, or of advice to government departments, are attributed by the team to the Society's inherent organisational weaknesses.

\section{Other organisations and bodies met by the team}

The team met a number of other officials and representatives of organisations, including the South African Medical and Dental Council, the Medical Association of South Africa (MASA); the National Medical and Dental Association (NAMDA); South African Health Workers' Congress (SAHWCO); Organisation for Appropriate Social Services in
South Africa (OASSSA); South African Association for Child and Adolescent Psychiatry and Allied Disciplines; Workers' Information Group; university staff; local and central government officials; and staff of hospitals.

\section{Medical organisations}

At the time of the investigation of the case of Steve Biko, MASA (which, among its other objectives, protects the interests of the medical profession in South Africa), came under intense international criticism. The team was told that the organisation has now moved towards a more olearly identifiable anti-apartheid stance.

Some of the other medical and related associations are of relatively recent date (for example, NAMDA, OASSSA and the South African Association for Child and Adolescent Psychiatry and Allied Disciplines) and were established, at least in part, to challenge apartheid in health care and to mitigate the effects of the system on those most directly involved (for example, detainees and their families).

\section{Universities}

The Universities of Witwatersrand and Cape Town have actively campaigned against apartheid policies and promoted integration of teaching and other facilities. The Universities of Pretoria and Stellenbosch are Afrikaans-speaking and the students admitted to their medical schools are predominantly white. The Medical University of South Africa admits only black undergraduate students, although most of the staff and many of the postgraduate students are white. The University of Natal admits mainly black and mixed-race students and a smaller number of Asians; many of the staff are Asian or black.

\section{Government departments}

Under the tricameral system, there are government departments dealing with health matters in relation to each racial group. The team met officials of the Department of National Health and Population Development ("General Affairs" division - all racial groups, including black Africans) and the Department of Health Services and Welfare Administration ("White Own Affairs" division). One recent development has been the appointment of a health minister with overall responsibility for health services and the role of ultimate adviser to the Treasury on these matters.

Officials from both departments described plans for the future, which in the case of the Department of National Health include the encouragement of the integration of services across all racial groups and the development of primary mental health care. The Chief Director indicated that there is a role available 
for the SPSA in advising on the integration of psychiatric services and providing the government with up-to-date information.

However, the head of the Health Services and Welfare Administration Department did not view the tricameral arrangements as inefficient and, in the opinion of the team, clearly saw his job as primarily that of maintaining health services for the white population.

\section{The impact of apartheid}

There was almost unanimous agreement among those whom the team met that the tricameral system is grossly inefficient and cannot be expected to provide basic health care to the whole population. In many important areas there is no provision whatsoever for black Africans; one example of this is the community psychiatric service in Johannesburg. De facto integration of services occurs (as in the Johannesburg example), but is at the instigation of individual clinicians and others, by direct action rather than negotiation whilst the relevant legislation remains in place. Such activities have recently been tacitly accepted at senior government level.

In the team's view, the SPSA has an important role to play in supporting members in their efforts with regard to the psychiatric services, integration of which has lagged behind that of other medical specialists.

The team draws attention to the effects of "economic" apartheid, which will persist after the possible ending of "political" apartheid and will continue to set practical limits on the equalisation of services.

\section{Impact of apartheid policies on mental health}

There is powerful evidence of the effects of apartheid, not only on service provision, but as a causative factor in mental illness in South Africa, particularly with regard to the black population. Material deprivation, segregation and gross social disruption and violence contribute in various ways to the development of both mental handicap and learning difficulties in children and mental illness in children and adults (including psychosis related to substance misuse).

The SPSA might have an important role in co-ordinating research on the psychological effects of torture and arbitrary detention and in developing codes of practice for use in such circumstances.

\section{Strategies for action}

Those whom the team met had thought deeply about these issues and there was some support for a complete "academic boycott", which in the medium term will leave doctors professionally isolated and may result in deterioration in services but which, it is believed, ultimately will speed the end of apartheid.

The majority view was in favour of a policy of "selective support", whereby active communication and assistance are offered only to those individuals and organisations in South Africa who advocate ending apartheid and can demonstrate that they are working towards the integration and equalisation of services.

\section{Conclusions}

\section{General conclusions}

(1) While the effects of apartheid on health and the provision of health services are well known and the assessment of these was not a primary function of the visit of the Royal College of Psychiatrists, the delegation was struck by the evident extremely destructive effects of this policy on health and other aspects of life in South Africa.

(2) There are many individuals in South Africa, in psychiatry and other fields, who have taken courageous stands in the support of the rights of patients and of equal and integrated health services and health policy, often at considerable personal risk. It is clear that the support of professional organisations for these individuals is often crucial.

(3) The visit took place at a time of considerable political change in South Africa and this was pointed out by all the representatives of organisations and individuals met by the visiting team. There have been changes in attitudes towards apartheid and its administrative, social and legal structures, but no fundamental change had occurred in apartheid legislation and the resulting structures at the time of the visit. (This has changed since the report was written, with the repeal of significant Acts and the ending of the State of Emergency.) Caution must therefore be applied to the optimism expressed about the recently improved circumstances.

(4) The staff of some institutions, including hospitals, have taken de facto action to integrate facilities and services. This has occurred in defiance of the law, but often with the apparent acquiescence of the authorities. These activities have generally been initiated by committed individuals and subsequently supported by the institutions in which they are employed.

(5) The issue of an 'academic boycott' is clearly of central importance in the development of policy by the Royal College of Psychiatrists. While 
some individuals met by the delegation supported a total boycott, the strongest body of opinion emerging from both medical and nonmedical individuals, groups, institutions and organisations was that a policy of 'selective support' would be most effective in the current circumstances. The clear recommendation of a policy of 'selective support' advanced in the AAAS report should be noted.

\section{Conclusions concerning the Society of Psychiatrists in South Africa}

(1) The organisation and its present senior officers appeared to be genuinely committed to antiapartheid policies, particularly in the area of the effects of apartheid on service provision.

However, communication of the Society's antiapartheid position is regarded as in adequate in some quarters. Certain decisions, e.g. where to hold national conferences, could be taken bearing this in mind.

(2) The SPSA is small, representing approximately 100 of the 200 psychiatrists in South Africa. Of this 100 , approximately half are in private practice. A substantial body of the remainder are employed by the academic departments of psychiatry of the universities.

(3) The delegation formed the view that the SPSA is, and has been, ineffective in several important areas. These include:

(i) communication with its own members

(ii) strategic pursuit of its policies

(iii) communication with other health-related organisations and professions

(iv) the provision of professional advice to government

(v) the lobbying of government

(4) The SPSA is seen by some of its members as geographically distant and this is related to the practice of choosing the Chairman and Secretary so that they are reasonably close to one another in this large country.

(5) The delegation became aware of the fact that, due to the small number of members and perhaps also the the structure of the SPSA, individual members perform a multiplicity of tasks, including considerable academic, representative and service commitments. This has, undoubtedly, contributed to the limited effectiveness of the SPSA.

(6) The SPSA is seen by other health-related organisations in the country, with creative and well-considered ideas on the future of psychiatric and mental health policies, as being potentially powerful but not having exercised that power. There has been some co-ordination within the 'Mass Democratic Movement', but little communication between it and the SPSA.

(7) The visiting team was informed by the Secretary of the SPSA that the strongest criticism of the organisation from within was from those who felt that the Society was 'too radical'. There are also many members of the Society who would welcome and support it being more active in confronting the problems faced by psychiatry in their country.

(8) The links between the SPSA and the Medical Association of South Africa have not been strong and MASA offers the Society no administrative or financial support. There is a body of opinion within the SPSA advocating a break with MASA in order to allow the Society to develop into a more progressive organisation. MASA is in a phase of transition itself and its staff told the visiting team that there could be a mechanism to permit affiliate membership of the SPSA for members of non-medical mental health professions.

(9) Discussions held by the delegation with government officials indicated that the Department of Health and Population Development (a 'General Affairs' department) would welcome additional authoritative professional advice on mental health matters. The visiting team was informed of the existence of the National Council for Mental Health, but also sees an important role to be played by a representative body of psychiatrists, such as the Society of Psychiatrists of South Africa, in providing such advice. The delegation formed the view that in the past this department has been over-reliant on the advice of individuals within the Civil Service, whose views do not necessarily reflect those of the psychiatric profession.

\section{Recommendations}

\section{General}

(1) The Royal College of Psychiatrists should accept and endorse the conclusions of the report of the American Association for the Advancement of Science Apartheid Medicine - Health and Human Rights in South Africa and its stance on apartheid, particularly its conclusion that a unitary and comprehensive health service will only emerge in South Africa when apartheid is completely abolished.

(2) The Royal College of Psychiatrists should consider adopting the policy of 'selective support'. This would mean eschewing official contact with any organisations or individuals in South Africa 
that continue to support apartheid, while maintaining active professional relationships with those who advocate ending apartheid and the development of an integrated, unitary health service and who can be seen to be working towards those ends. (As an example, those responsible for education in medicine and nursing are likely to be helped in their difficult task by support, following the recent desegregation of such education, given the enormous discrepancies which currently exist in the education provided for different racial groups.)

(3) In view of the pace of change possible in South Africa, the President of the Royal College of Psychiatrists should review the time-scale of the College's activities and consider whether an official visit should take place in advance of the two years previously proposed by the Resolution passed by the Annual Meeting in 1989, in order to examine the role and anti-apartheid activities of the Society of Psychiatrists of South Africa (see particular recommendations below).

(4) The delegation believes that there would be significant advantages of continuity if the delegation which makes the future official visit includes those members who made the preliminary visit and this is recommended. The impact of the future visit and recommendations stemming from it are important, and it is suggested that the future delegation should be augmented by one or two additional members and that one of these should be a very senior member of the College, such as an ex-President. The delegation should be multi-racial.

\section{The Society of Psychiatrists of South Africa}

(1) The Royal College of Psychiatrists should take note that the SPSA may wish to examine its current position in relation to the provision of psychiatric, mental health and primary health care services in South Africa.

(2) The Society could adopt a higher profile as a representative professional body giving advice to the South African government. It could liaise more actively with other organisations such as MASA, NAMDA, OASSSA and SAHWCO, in order that co-ordinated, multidisciplinary opinions and responses can be provided.

(3) The delegation thinks that, if the Society wishes to become more effective, it should implement organisational changes which were under consideration at the time of the visit, e.g., lengthening the term of office of the Chairman and Secretary.

Fiona Caldicott RichaRd WiLliams PETER RICE

Approved by the Executive and Finance Committee

February 1991

\section{The Morris Markowe Prize}

Entries for this public education prize should be submitted by 1 May 1991.

Last year's entries were varied and interesting, but few authors had the knack of making what they had to say pithy and pertinent for lay readers. We are not looking for under-referenced, watered-down scientific papers. Be erudite by all means, but be a journalist too: keep it simple, keep it short, make the message plain, and on an up-beat. A paper which makes excellent use of a case history is available from Deborah Hart at the College. The College's 'Help is at Hand' leafets are also good examples.

So, if you want to have a go, set your sights a little low-and have fun!

Bruce PItT 